\title{
EL ANTILIBERALISMO COMO CLAVE DE \\ LA OBRA DE KOSELLECK
}

\section{ANTILIBERALISM AS KEY TO KOSELLECK'S WORK}

\author{
Alfonso Galindo Hervás*
}

Resumen

En este artículo defiendo que la crítica del liberalismo puede considerarse una clave que permite unificar el proyecto teórico de Koselleck. Su antiliberalismo tiene sus orígenes en la influencia del pensamiento de Schmitt, y se concreta en la tesis de Crítica y crisis y en el objetivo de revitalizar el lema Historia magistra vitae.

* Profesor de Filosofía Política en la Universidad de Murcia (España). Editor y autor de numerosos volúmenes y artículos de filosofía política, historia de los conceptos políticos y filosofía y cine. Ha escrito los siguientes libros: (2003) La soberanía. De la teología política al comunitarismo impolítico, Res $\mathrm{Pu}$ blica, Murcia. (2005) Política y mesianismo. Giorgio Agamben, Biblioteca Nueva, Madrid. (2006) Cincuenta mitos, IV Premio de Ensayo Miguel Espinosa. Editora Regional, Murcia. (2014) (con E. Ujaldón) La cultura política liberal. Pasado, presente y futuro, Tecnos, Madrid. (2015) Pensamiento impolítico contemporáneo. Ontología (y) política en Agamben, Badiou, Esposito y Nancy, Sequitur, Madrid. (2016) (con E. Ujaldón) Diez mitos de la democracia, Almuzara, Córdoba.

\section{Palabras clave:}

Koselleck - Schmitt - liberalismo - progreso - historia de los conceptos.

\section{Abstract}

In this article I defend that the criticism about the liberalism can be considered a key in order to unify the Koselleck's theoretical projet. His point of view anti-liberal has its origins in the influence of Schmitt's thought, and it is stated explicitly in the thesis from Crítica $y$ crisis and the revitalization of motto Historia magistra vitae.

Keywords:

Koselleck - Schmitt - liberalism - progress - history of concepts.

1. Una conclusión y una justificación para comenzar

La relevancia intelectual de Reinhart Koselleck está fuera de duda actualmente. Ello no impide que en el ámbito académico español 
sea una figura poco conocida. No es preciso buscar otra causa de tal situación que la propia debilidad de la "academia"1 española, sus universidades, foros y editoriales. Pero si quisiéramos añadir un argumento, no parecería exagerado aludir al contexto filonazi en el que hunde sus raíces la obra del catedrático de Teoría de la Historia. Dicho contexto pasa, entre otros datos, por la influencia de Carl Schmitt, autor igualmente evitado hoy por su pasado nazi -pero que, a pesar de ello, constituye el referente oculto de muchas de las teorías contemporáneas sobre lo político, incluidas varias ubicables en eso que llamamos "izquierda"2.

Esta breve alusión es relevante en este artículo dado que en él se pretende mostrar y analizar los elementos antiliberales presentes en el pensamiento de Koselleck, y éstos tienen su fuente principal en las ideas del antiliberal Schmitt. Así, una comprensión cabal del antiliberalismo del catedrático de Bielefeld exige mostrar primeramente el correspondiente de

1 Los argumentos presentes en este artículo fueron debatidos en el Seminario de pensamiento económico y filosofía política "Laureano Figuerola" de la Universidad Rey Juan Carlos de Madrid. Deseo agradecer a los participantes sus comentarios. Han sido también muy valiosas las sugerencias de José Luis Villacañas. Naturalmente, las deficiencias del texto sólo son atribuibles a mí. Araucaria. Revista Iberoamericana de Filosofía, Política y Humanidades, $N^{\circ} 21$. Primer semestre de 2009. Págs. 44-62.

2 Una forma de atisbar la dimensión antiliberal de Schmitt consiste en reparar en cierto pensamiento que evidencia una deuda con él: el de los Cacciari, Agamben, Nancy, Zizek, Ranciere, Mouffe, etc. No sería justo afirmar que estos pensadores son "schmittianos" si por tal entendemos que asumen las propuestas políticas de Schmitt. Pero sí lo son en la medida en que ciertas tesis de éste resultan indispensables en el desarrollo de sus propias filosofías sobre lo político. En este sentido, quizá nadie como Walter Benjamín ejemplifique la simultaneidad tanto del rechazo más radical del pensamiento de Schmitt como de la insuperable deuda con él, hasta el punto de poder considerárselo el arcanum de su propia producción filosófica.
Schmitt. Esto se refuerza al constatar que Koselleck no es un filósofo o teórico de lo político, como lo es Schmitt. Ello implica el que su obra, donde la reflexión sobre la historia o los conceptos se funde con la de lo político o el Estado, sea ampliamente deudora de las tesis schmittianas sobre el Estado, la soberanía, el dualismo público- privado, la enemistad, etc. Sintetizando mucho podría decirse que los elementos antiliberales que puedan hallarse en el pensamiento de Koselleck constituyen, entre otros muchos, un índice, a la par que un factor obvio, de la influencia de las tesis de Schmitt en su obra. Defenderé que la presencia de dicha influencia puede servir como criterio de la unidad del pensamiento de Koselleck.

Por lo demás, el que a estas alturas, cuando parece consagrada en Occidente la fórmula mixta recogida bajo la expresión "democracia liberal", visitemos los argumentos antiliberales de pensadores tan peligrosos como Schmitt y Koselleck, merece una breve justificación que trascienda el mero interés académico.

La perspectiva política, realista y conservadora, del jurista y del historiador contribuye a la comprensión de distintos fenómenos sociales contemporáneos: tanto los relativos a la emergencia de nuevas identidades colectivas, como los que constituyen excepciones que cuestionan la plena realización (incluso realizabilidad) del modelo liberal-democrático, que al postularse como encarnación del derecho y la razón se hace impotente para aprehender el carácter conflictual de lo político ${ }^{3}$.

3 Es la tesis de Mouffe en El retorno de lo político, trad. M. A. Galmarini, Paidós, Barcelona, 1999, p. 12. Un reciente ejemplo de la cándida apoliticidad de cierto liberalismo se halla en J. Mosterín, La cultura de la libertad, Espasa-Calpe, Madrid, 2008. El autor defiende la utopía de un mundo sin política y sin Estados, gobernado por la neutralidad de la ciencia y de sus expertos, por los intercambios libres y racionales, en progreso imparable. 
El punto de vista realista de estos pensadores puede contribuir a cuestionar el ingenuo cognitivismo que olvida que las realidades que consideramos conquistas, tales como la vida democrática, carecen de un fundamento racional si por tal hemos de entender exento de decisiones, apuestas y avatares históricos. Dicho de otro modo, el realismo político nos recuerda el fundamento político de la democracia, entendiendo por tal que su legitimidad no se alcanza sólo desde la teoría, sino que implica una praxis determinada que evidencie la voluntad de preservar sus valores propios ${ }^{4}$.

En este contexto no está de más recordar que el estatalismo afín al realismo schmittiano, si bien es cierto que encarna la comprensión más totalitaria de la forma estatal, surge de una agudísima conciencia de que fue dicha forma de gobierno, y además en su versión radical -el Estado absoluto del siglo XVIII-, la que posibilitó el surgimiento, la estabilización y el triunfo de la sociedad liberal. Que ello no fuese fruto querido ni previsto (¡ni siquiera compatible!), no implica asumir las soluciones de Schmitt y de Koselleck, pero tampoco renunciar a su brillante diagnóstico en aras de un liberalismo reducido a mentirosa y tópica caricatura de antiestatalismo. Y ello porque el diagnóstico es tan persuasivo que no sólo permite propuestas políticas "schmittianas", sino igualmente otras conscientes de que también el Estado es aún garantía de derechos individuales -y, en esta medida, de sociedad civilallí donde las distintas formas de poderes de suyo no políticos (económicos, científicos, mediáticos, religiosos, etc.) vehiculan y gestionan conflictos que alcanzan una intensidad existencial, propiamente política, aplastando sin control alguno a los individuos. Cuando esta conciencia declina, la apoliticidad y el an-

4 La perspectiva del liberal Rorty, por ejemplo en La prioridad de la democracia sobre la filosofía, sería compatible con este anticognitivismo. tiestatalismo liberales se transmutan en abierta impoliticidad, la de aquéllos que no han conseguido comprender lo político sino desde las categorías y teorías de Schmitt y que, por ello mismo, reducen toda alternativa frente a ellas a trascenderlas $a b$ integro mediante fórmulas que implican todo lo totalmente opuesto a lo implicado en las mismas, a saber: misticismo antiteológico y antijurídico (anómico, mesiánico) revestido de apariencia ontológica, inacción e irrepresentabilidad absolutas ${ }^{5}$.

En suma, el realismo político de Schmitt y de Koselleck puede enseñar a un pensamiento político defensor de la democracia que lo político constituye una esfera determinada por el conflicto, la necesidad de construir formas de unidad y la imposibilidad de sustraerse a la decisión. De ahí que el reto político de una sociedad plural pase por arbitrar mecanismos de regulación del disenso (más que de forja de consensos) que permitan el surgimiento de identidades plurales compatibles. Al no cuestionar el individualismo y priorizar la libertad personal frente a lo político-estatal, cierto liberalismo sólo puede establecer límites al egoísmo desde la ética o la propia economía. Pero si sólo cabe esperar la emancipación de (de, por y en) las esferas de la moral y de la economía, la emancipación alcanzable será meramente moral y económica, corriéndose el riesgo de permanecer en una esclavitud política o, cuando menos, en la crisis política permanente.

\section{El arcanum antiliberal de Koselleck}

El antiliberalismo de Koselleck tiene como antecedente inmediato su con-ciencia,

5 Es el caso de Jean-Luc Nancy o Giorgio Agamben. También de determinadas propuestas y textos de Derrida, Negri y Hardt. Sobre este tema, me permito remitir a mi libro La soberanía. De la teología política al comunitarismo impolítico, Res Publica, Murcia, 2003. 
netamente schmittiana, de que no existe (histórica y estructuralmente) el liberalismo (y lo que implica: eso que es habitual denominar "sociedad civil") sin el Estado y que, una vez constituida la sociedad civil burguesa a instancia de dicho Estado, ésta se alza como el agente corrosivo par excellence de su soberanía, destinándonos a una situación de crisis permanente y acelerada. Bastará por ahora con una significativa frase: "La utopía burguesa es el 'hijo natural' de la soberanía política absolutista. Con ello el Estado sucumbe a sus propias condiciones".

Los argumentos antiliberales del autor de Futuro pasado son consecuencia directa de una concepción de lo político que remite su especificidad al antagonismo existencial y, en esta medida, justifica el Estado a partir de la evitación de la guerra civil, haciéndolo preferible a su ausencia. Una concepción de lo político que margina la cuestión de la legitimidad del poder, remitiéndola a la eficacia en la conducción de la lucha existencial de un pueblo ${ }^{7}$. Si Carl Schmitt fue quien teorizó, con un alto grado de abstracción, dicha visión antiliberal del Estado y de lo político, la obra de Koselleck puede comprenderse como un desarrollo de la misma concretada en el estudio de los procesos históricos concretos que supusieron la emergencia de la sociedad civil, su inconsciencia política $y$, en esta medida, su larvada tarea antiestatal, cuyo desenlace fue la revolución. Así, mientras que el concepto de lo político de Carl Schmitt implica la denuncia de la moralización liberal del Estado como el índice (y el factor) más claro de la disolución de su soberanía (con las nefastas consecuencias que se seguirían de ello), el an-

6 R. Koselleck, Crítica y crisis del mundo burgués (en adelante, CC), trad. R. de la Vega, Rialp, Madrid, 1965, p. 336.

7 Sobre este punto, cf. J. L. Villacañas, "Histórica, historia social e historia de los conceptos políticos", Res Publica, 11-12, 2003, pp. 69-94. tiliberalismo de Koselleck se deja comprender como una denuncia de la moralización liberal de la Historia (esto es, de la creación de la Filosofía de la Historia) por constituir el índice y el factor más claros del olvido de lo político y de la crítica antiestatal conducentes a la crisis política permanente.

La aportación de Koselleck en lo referente a la crítica del liberalismo se remite, pues, a una explicación de la revolución o crisis política, elevada a estructura interna de la Modernidad y del tiempo presente, que atiende a los procesos históricos que estarían en su base. La obra de referencia sobre este punto es Crítica y crisis, de 1959.

Pero el antiliberalismo de Koselleck no se limita a la presentación de la, a su juicio, patogénesis del mundo moderno. Junto a ello, existe otro núcleo argumentativo que se deja explicar a partir de dicho antiliberalismo, permitiendo establecer una continuidad en su obra por cuanto da cuenta del magno programa histórico-conceptual. Se trata de sus alusiones, comprensibles como un intento de revitalización, al lema ciceroniano historia magistra vitae. Con tal lema quedaría nombrada la crítica de Koselleck a un mundo, el moderno bajo cuya influencia aún vivimos, que destina al hombre a la necesidad de novedad permanente $y$, en esta medida, a la insatisfacción y a la crisis permanente. A su juicio, la modernidad se construye a partir de la emergencia de un abismo entre las experiencias acumuladas y las expectativas por venir. Dicho abismo ha consagrado la imposibilidad de aprender de la historia, instalándonos en un mundo acelerado y fagocitador de novedades, un mundo que ignora las estructuras duraderas que permiten el surgimiento de algo verdaderamente nuevo, hurtando al hombre los recursos para el sosiego, la seguridad y el orden. 


\section{Los argumentos antiliberales de Carl Sch-} mitt

Las reflexiones de Schmitt sobre el liberalismo no constituyen ningún texto autónomo, sino que aparecen diseminadas en múltiples escritos. Como veremos, algo análogo puede afirmarse respecto de Koselleck. Junto a argumentos puntuales que cuestionan algún rasgo del pensamiento liberal, lo habitual es que los elementos antiliberales presentes en la obra de Schmitt y de Koselleck deban ser inferidos de sus concepciones sobre lo político, el Estado o la historia, por citar sólo algunos conceptos nucleares de sus filosofías. En el caso de Schmitt, es su concepción general de lo político la que se deja comprender como una concepción esencial o estructuralmente antiliberal.

A esta circunstancia se añade la propia ausencia de una caracterización acabada o cerrada de qué sea eso del pensamiento liberal. Ello se agudiza con el hecho de tener que limitarnos a un examen de los elementos antiliberales de Schmitt y de Koselleck tomando como referencia su conceptualización del liberalismo, que, además de ofrecérsenos de modo asistemático, es igualmente parcial, respondiendo propiamente a una de entre las múltiples tipologías de liberalismo que cabe recrear.

Todo esto hace inexcusable determinar sintéticamente algunos rasgos mínimos atribuibles genéricamente al liberalismo. Pero subrayando tanto su abstracción y revisabilidad, como el hecho de que la selección de los mismos no puede evitar ser informada por la crítica al liberalismo de Schmitt y de Koselleck. Dicho de otro modo: recrearé algunos tópicos liberales y su crítica guiándome para su propuesta tanto de las caracterizaciones habituales (y menos cuestionables a priori) del liberalismo, como de los mismos argumentos críticos de nuestros pensadores de referencia. Esta circularidad no constituye un problema que invalide el desarrollo de la exposición en la medida en que, como podrá comprobarse, la comprensión schmittiana y koselleckiana del liberalismo se atiene a los tópicos usuales.

En general, resultaría aceptable remitir el liberalismo a la voluntad de racionalizar los dispositivos disciplinarios del gobierno usando como criterio los límites procedentes de los derechos y libertades individuales y, como instrumento, la regulación jurídica de su acción mediante el parlamentarismo y el constitucionalismo. Todo ello presidido por la neutralidad del Estado, factor e índice de pluralismo. Desde esta caracterización, los conceptos que habitual-mente se usan para aprehender la especificidad del liberalismo son, entre otros: libertad, racionalidad, individuo/individualidad, pluralismo, parlamentarismo, neutralidad estatal, consenso, etc.

Como señalé, es la concepción schmittiana de lo político la que se deja comprender como una concepción esencial o estructuralmente antiliberal. Dicha concepción tiene su clave de bóveda en la comprensión de la soberanía a partir de dos elementos: la representación del orden concreto (nacional) y el monopolio sobre el caso excepcional, que implica tanto la decisión que inaugura un estado de excepción, como la decisión de guerra e identificadora de un enemigo (que no son sino la determinación material del criterio formal de soberanía a partir de la decisión sobre lo excepcional).

A partir de esta síntesis del concepto schmittiano de lo político, su antiliberalismo se puede aprehender a partir de dos núcleos conceptuales: uno relativo a la comprensión de lo político y del Estado, que es contrario a la pretendida neutralidad estatal propugnada por el liberalismo, y otro relativo a la libertad y lo que ella implica (individualismo, pluralismo y escisión entre lo público y lo privado). Como la posición de Schmitt respecto de ambos nú- 
cleos es coherente con su concepción de lo político, conviene exponer ésta brevemente.

\subsection{Lo político y el Estado}

Schmitt estudia la esencia de lo político con el fin de iluminar el origen y la esencia del Estado. Ello implica que el alcance de la soberanía estatal constituya la consecuencia inevitable de su comprensión de lo político ${ }^{8}$. En su objetivo de hallar la especificidad de esta esfera de acción, desarrolla en El concepto de lo político una concepción antropológica pesimista. Frente a la cándida confianza ilustrada (liberal) en la educación de las capacidades humanas, claramente visible en las obras de los ilustrados escoceses, defiende un esencial déficit ontológico en el ser humano que explica su tendencia al mal, desencadenante a su vez de la secuencia lógica que conduce a la postulación de la necesidad de la autoridad decisoria absoluta. Sólo si se defiende la esencial conflictividad humana se puede explicar la emergencia del ámbito de lo político, así como su figura por excelencia, el Estado. Al contrario, cuando aumenta la fe en la bondad natural humana, crece la crítica anárquica, y las leyes son sustituidas por los lazos éticos y afectivos ${ }^{9}$.

Lo político es posible porque hay enemigos y la guerra es posible, tornándola efectiva en el presente ${ }^{10}$. La razón es que la guerra es el auténtico caso de excepción (urgido de decisión) desvelador de la politicidad y de la nor-

8 De lo que se trata fundamentalmente es de la relación y correlación de los conceptos de lo estatal y de lo político por una parte, y de los de guerra y enemigo por la otra”. Prólogo, en C. Schmitt, El concepto de lo político, trad. R. Agapito, Alianza, Madrid, 2002.

9 Ibid., pp. 89s.

10 Ibid., pp. 58, 62, 64ss. Sobre las dificultades de la dialéctica entre posibilidad y efectividad en el concepto schmittiano de lo político, cf. J. Derrida, Políticas de la amistad seguido de El oído de Heidegger, trad. P. Peñalver y F. Vidarte, Trotta, Madrid, 1998, pp. 106, 147, 155. malidad de las cosas. De ahí que si no existe como posibilidad, se llegue a una despolitización ${ }^{11}$. Sólo porque hay enemigos y posibilidad efectiva de guerra, surge lo político y el Estado como su forma. Dicho Estado halla legitimidad en su capacidad de decidir quién es enemigo, combatirlo e instaurar la paz y la normalidad ${ }^{12}$. Pero no sólo: también representa una realidad trascendente, la unidad nacional ${ }^{13}$. Ambos extremos explican su carácter teológico-político. Al igual que la Iglesia católica, se enfrenta a la ineliminable conflictividad humana produciendo derecho y representando una verdad trascendente ${ }^{14}$.

En la convulsa época weimariana, Schmitt reclamó un Estado situado por encima del parlamento, un Estado capaz de combatir al enemigo y garantizar la protección. A sus ojos, el Estado alemán adolecía de la enfermedad normativista, cuyos síntomas son tanto la ausencia de referencia al orden trascendente como la incapacidad de decisión. Se trataba, a su juicio, de un Estado dominado por el objetivo de la neutralidad, que es el dogma de una época presidida por el crecimiento de la técnica, y que ingenuamente pretende disolver los conflictos sin tomar decisiones ${ }^{15}$. Schmi$\mathrm{tt}$, al contrario, considera ingenuo sostener la viabilidad de un funcionamiento meramente neutral y automático del Estado y su ordenamiento jurídico, como se pretende en el mode-

11 Ibid. pp. 65s.

12 Ibid., pp. 74ss.; C. Schmitt, Teología política, en Estudios Políticos, trad. F. J. Conde, Cultura española, 1941, pp. 44s.

13 C. Schmitt, Teoría de la Constitución, trad. F. Ayala, Editora Nacional, México, 1952, pp. 24ss., 50, 88, 95, 237ss., etc.; Sobre los tres modos de pensar la ciencia jurídica, trad. M. Herrero, Tecnos, Madrid, 1996, pp. 14-16.

14 C. Schmitt, Catolicismo y forma política, trad. C. Ruiz Miguel, Tecnos, Madrid, 2000, pp. 17, 20, 23, 26; Teoría de la Constitución, op. cit., p. 245.

15 C. Schmitt, La época de la neutralidad, en Estudios Políticos, op. cit., pp. 15, 23s. 
lo liberal de Estado, ya que la presunta supremacía de la impersonal ley no puede ocultar que tras el funcionamiento de las mismas se oculta la voluntad soberana de los hombres ${ }^{16}$. La teología política de Schmitt se halla aquí: en que, frente a la neutralización despolitizante, $\mathrm{e}$ instalado en una clara consciencia del origen irracional de todo orden, afirma lo político y la forma estatal, así como la existencia de un orden concreto representado por el soberano.

\subsection{Lo apolítico y la sociedad liberal}

Si todas las teorías políticas propiamente dichas presuponen que el hombre es "malo", el optimismo antropológico liberal, que según Schmitt pretende poner el Estado al servicio de la sociedad, constituiría un índice y un factor más de ausencia de sentido político. En la medida en que dicho sentido halla en la forma estatal su índice y su factor ejemplares, la consecuencia es que el liberalismo carece de una teoría positiva o una reforma propia del Estado. En lugar de ello, niega el Estado (aunque nunca radicalmente) $y$, en esta medida, lo político, que remite a la ética y a la economía, pretendiendo -ingenuamente- soslayarlo. Aunque históricamente haya determinado prácticas políticas, el liberalismo carece de una idea específicamente política. Existen políticas liberales concretas en tanto que crítica de las limitaciones a la libertad individual, "pero lo que no hay es una política liberal de carácter general, sino siempre únicamente una crítica liberal a la política"17.

A juicio de Schmitt, la razón de la apoliticidad liberal es la negación de lo político que implica todo individualismo ${ }^{18}$. La desconfian-

16 Esta visión del Estado de Derecho se evidencia en su crítica a Kelsen. Cf. Sobre los tres modos..., op. cit., pp. 9-26; Teología política, op. cit., pp. 53s., 66-69.

17 El concepto de lo político, op. cit., p. 98.

18 Ibid., pp. 73s. Schmitt detectó el germen del individualismo moderno ya en Hobbes, en concreto, en la za frente al Estado y a la política se explican a partir de los principios de un sistema para el cual el individuo es y debe seguir siendo tanto terminus a quo como terminus ad quem. Toda constricción o amenaza a la libertad individual, por principio ilimitada, o a la propiedad privada o a la libre competencia, es "violencia" y por lo tanto mala. Para el publicista, lo que este liberalismo deja en pie del Estado y de la política es únicamente el cometido de garantizar las condiciones de la libertad y de apartar cuanto pueda estorbarla ${ }^{19}$. Ello explica la imposibilidad de que una sociedad liberal pueda pedir en caso extremo el sacrificio de la propia vida -como debe poder hacerlo toda unidad política, pues tal decisión pertenece, como todo lo esencial en una sociedad liberal individualista, a la privacidad ${ }^{20}$.

La ignorancia de lo político y del Estado que señala esta desmilitarización afín al liberalismo, u otras como la tipificada en las declaraciones antibelicistas, "equivale a" o "determina el” recurrir a categorías y principios de otras dos esferas: ética y economía. Así, por ejemplo, la lucha política se transforma en competencia económica o discusión moral, la regulación del conflicto en búsqueda apolítica del consenso. Según Schmitt, el objetivo es someter el Estado y la política a una moral individualista (iusprivatista) y a categorías económicas ${ }^{21}$. Por ello declara que este individualismo liberal es incompatible con la democracia, ya que ésta es homogeneidad y equivalencia (tratar igual sólo a los iguales y excluir a los heterogéneos), mientras que el liberalismo implica pluralismo, a la par que viene exigido por su defensa. Dicho pluralismo no sólo requiere mantener la

distinción entre el fuero interno y externo, lo privado y lo público. C. Schmitt, El Leviatán, trad. F. J. Conde, Rivadeneyra, Madrid, pp. 51, 86-89, 93ss., 109ss., $120,130$.

19 El concepto de lo político, op. cit., pp. 98s.

20 Ibid., p. 77.

21 Ibid., p. 100. 
escisión entre ámbito público y privado, sino que exige (a la par que posibilita) la neutralidad institucional, definitivamente liquidadora de lo político. Schmitt no tiene duda de que el liberalismo es afín a un Estado neutral, meramente técnico, excluyente de lo político, que es decisión de la excepción, es decir, que posee un fundamento no-racional, no mediable, no deducible. El liberal pretendería excluir de la política y del Estado los contenidos normativos, potencialmente conflictivos, mostrando el anhelo de una política reducida a actividad instrumental neutra. A tal fin sirve la escisión público-privado, que posibilita relegar al ámbito de la privacidad toda dimensión normativa $^{22}$.

Pese a todo, Schmitt concluye que el liberalismo no lograría erradicar ni el Estado ni la política, pues lo político puede alcanzarse a partir de cualquier ámbito. Surge entonces un imperialismo económico capaz de disponer de medios bélicos sin control alguno, pues al pretender soslayar la enemistad determinante de lo político, desconocerá sus criterios y límites, tornándose absoluto (aunque disfrazado) ${ }^{23}$.

\section{El triunfo histórico de la apoliticidad li- beral}

Para Schmitt, lo político es ámbito de conflicto y de búsqueda de formas de unidad, de ahí que la clave de su crítica al liberalismo radique en que éste niega la política o, mejor, la encubre bajo lo jurídico y la transmuta en

22 Esta crítica del individualismo subyacente a las distintas actitudes defensoras de los derechos del fuero interno, esconde una concepción de la moral y de su relación con el Estado que implica reducirla a una suerte de hegeliana eticidad estatal según el modelo de comunidad nacional. Cf. M. Kaufmann, ¿Derecho sin reglas? Los principios filosóficos de la teoría del Estado y del Derecho de Carl Schmitt, trad. J. M. Seña, Alfa, Barcelona, 1989, pp. 48-56. competencia económica o discusión ética. Pero, a su juicio, el refugiarse en la apoliticidad constituye la peor forma de acción política ${ }^{24}$.

La liquidación de la soberanía estatal merced a su reemplazo por una sociedad gobernada por principios morales y económicos constituye igualmente un proceso histórico. Dicho proceso, sintetizable desde categorías schmittianas como un reemplazamiento de lo político-estatal por lo apolítico-social, es estudiado por Koselleck desde la asunción de los presupuestos teóricos de Schmitt aquí recreados. La obra de referencia es la temprana Crítica y crisis. Podría decirse que ésta surge como desarrollo del siguiente párrafo de Schmitt:

"Desde sus comienzos el pensamiento liberal utilizó contra el Estado y la política el reproche de la 'violencia'. Esto no habría pasado de ser uno de esos insultos más o menos inocuos propios de la lucha política si su imbricación en una gran construcción metafísica y la correspondiente interpretación de la historia no le hubiesen conferido un horizonte más vasto y una mayor fuerza de convicción. La Ilustración dieciochesca veía ante sus ojos una línea simple y clara de progreso ascendente de la humanidad. Tal progreso consistiría ante todo en la perfección intelectual y moral de la humanidad"25.

Schmitt alude al vínculo entre la fe en el progreso propia del siglo XVIII, el desarrollo económico y técnico del XIX y el parlamentarismo. Aunque dicha alianza perdió su sentido tras la defunción del Estado absolutista, pese a ello se mantiene su concepción progresista y moralizadora de la Historia.

Frente a dicha filosofía de la Historia, Koselleck ostenta una conciencia schmittiana: el

C. Schmitt, Escritos de política mundial, trad. H. Cagni, Heracles, Buenos Aires, 1995, pp. 45ss.

25 El concepto de lo político, op. cit. , p. 101. 
liberalismo no es una planta natural, sino que tiene unas condiciones históricas muy precisas que es necesario identificar. Así, el surgimiento de la sociedad liberal no se explica sin la emergencia de un nacionalismo procurado estatalmente y que constituye el ámbito de posibilitación de una economía homogénea que evidencia la presencia del impulso del Estado tras ella. Igualmente, sólo el Estado fue capaz de acabar con la sociedad estamental, permitiendo de este modo la emergencia de una sociedad civil plural que finalmente se enfrentará a él. En conclusión, el liberalismo (y su rostro más conocido: la sociedad civil) depende estructural e históricamente del Estado, si bien su desarrollo conlleva la destrucción del mismo, abocando a la sociedad a una situación de crisis política permanente y acelerada que hace preferible un Estado fuerte.

Esta conciencia histórica es propia de países que han llevado a término sus revoluciones tardíamente, como sucede con Alemania. En el caso de la temprana Inglaterra aún fue posible hurtar a la conciencia los factores históricos, y en esta medida políticos, que sostenían la emergencia y legitimidad de la nueva sociedad diferenciada del Estado. Ello explica el que los ilustrados escoceses aún pudiesen presentar el advenimiento de la political society como fruto maduro de una naturaleza humana polished, esto es, altamente perfeccionada por el mero despliegue de sus posibilidades naturales.

Ésta no es la convicción del schmittiano Koselleck, sabedor de que también en Inglaterra murieron reyes desde 1642 a 1689. En Crítica y crisis se evidencia la deuda contraída con Schmitt, entre otros rasgos, en la conciencia de que hay un punto en el que el Estado ya no puede soportar la sociedad liberal que él mismo ha posibilitado. La razón es la ingenuidad o falta de conciencia de la nueva sociedad burguesa, que no comprende que la crítica conduce inexorablemente a un proceso de crisis netamente político. Es su conciencia de apoliticidad lo que focaliza como causa oculta de crisis política, mostrándose de este modo que la pretendida apoliticidad no era tal. Dicho de otro modo: la burguesía matará al factor que la ha hecho posible, permaneciendo en la crítica permanente $y$, en esta medida, en la revolución permanente y acelerada.

La tesis de partida de Crítica y crisis es que la raíz de la actual crisis, resultado de la historia europea devenida universal, se halla en el siglo XVIII. En concreto, en la emergencia de la sociedad burguesa y su filosofía de la Historia, que invocó principios morales y a la propia Humanidad contra el Estado absolutis$\mathrm{ta}^{26}$. Desde esta convicción, Koselleck estudia el nexo entre el surgimiento de la filosofía de la Historia y la crisis que desde 1789 determina el acontecer político universal, es decir, la función política que desempeñó el pensamiento ilustrado en el seno del Estado absolutista.

Para el análisis histórico de esta tesis schmittiana- recrea la estructura política del absolutismo, que considera antecedente de la Ilustración. Ésta se desarrolló a partir de aquél y bajo la misma forma estatal, provocando más tarde su derrumbamiento. El historiador de Bielefeld explica que el monopolio sobre la paz hacía recaer sobre el monarca la responsabilidad de una dominación absoluta exenta de constricciones morales, que quedaban remitidas a la conciencia de los súbditos ${ }^{27}$. Al igual que sucedía en Schmitt, Hobbes es el autor privilegiado para ilustrar la génesis de la moderna teoría del Estado a partir de las guerras civiles religiosas y, en concreto, para identificar el germen del pensamiento burgués del estado de derecho. La originalidad del inglés radicaría en encarar el problema de cómo lograr la paz evidenciando la dimensión ideológica de la

27 CC, p. 37. 
conciencia. La subsistencia del Estado requiere una moral racional que acepte la soberanía absoluta como necesidad moral. Con ello liquida la dimensión política de las convicciones morales, pues para la razón, abocada a la alternativa guerra-paz, coinciden moral y política $^{28}$. La discrepancia entre ámbito interno y externo, que según su análisis es factor de guerra civil, es puesta por Hobbes al servicio del Estado al hacer posible la obediencia (meramente externa) a una ley formal y que no exige convicción. Lo decisivo es que la Ilustración ampliará el ámbito interior, permaneciendo el súbdito ajeno a la responsabilidad política. La tesis schmittiana de Koselleck es que la necesidad de paz lleva al Estado a conceder al individuo un ámbito interior políticamente indiferente, moral, que supuso un foco de inestabilidad del sistema absolutista ${ }^{29}$.

Koselleck se sirve de distintos autores para proponer una interpretación de la Ilustración que subraya su carácter de respuesta a la situación reinante bajo un Estado absolutista. Con Locke la jurisdicción moral exterior (the Law of Private Censure) adquiere un significado constitutivo para la ciudadanía, evidenciando su eficacia política indirecta. En Ensayo sobre el entendimiento humano confiere a los juicios morales carácter de ley, siendo su detentador no el individuo sino la society formada en los clubs. Los ciudadanos no quedan ya subordinados exclusivamente al Estado, sino que constituyen una society que desarrolla sus propias leyes morales. Tal ampliación del ámbito interior privado hacia el campo público mediante su elevación a categoría de ley fue posible por la capacidad de censura que implicaba ${ }^{30}$. Locke interpreta las opiniones morales desde su función social, pero no para deducir de ellas

28 CC, pp. 57ss. Esta afinidad entre absolutismo y razón explicaría el que Hobbes no viese que ésta puede emanciparse y entrar en declive.

30 CC, pp. 93 s. 97 s. el Estado, como Hobbes, sino convirtiéndolas en permanente ejecución del juicio social y en índice del poder de la society ${ }^{31}$.

En el mundo absolutista continental, las formas de acción de la nueva societé fueron coherentes con su imposibilidad de expresar políticamente su relevancia social en el Estado absolutista. La nueva élite se reunió en lugares apolíticos, instituciones toleradas por el Estado donde desarrollaba tareas sociales. En este sentido, las logias constituyen la configuración típicamente burguesa de un poder indirecto (moral) en el seno del Estado ${ }^{32}$. A juicio de Koselleck, la clave de su éxito radicaba en la premisa del secreto -cuyo correlato era el dualismo entre moral y política-, que resultaba fundamental para la independencia de la nueva forma social burguesa ${ }^{33}$. El secreto y la carencia de poder directo generó una jurisdicción específicamente moral orientada a fundar una unidad social de carácter moral y cuya capacidad coactiva radicaba en la presión social. La apoliticidad masónica implicaba una politicidad revolucionaria indirecta y oculta, cuyo desenlace se dará cuando la crítica conduzca a la nueva élite a exigir una nueva forma política, separándose del Estado para acabar dominándolo. Es lo que manifiestan Schiller y Voltaire $^{34}$.

Con la finalidad de mostrar el vínculo entre la crítica burguesa, su toma indirecta del poder y la crisis política, Koselleck argumenta que la agudización de la crisis se corresponde dialécticamente con el encubrimiento de su significación política merced a la filosofía burguesa de la Historia, que la disimula como mero tribunal moral que culmina el proceso crítico iniciado por la burguesía contra el Es-

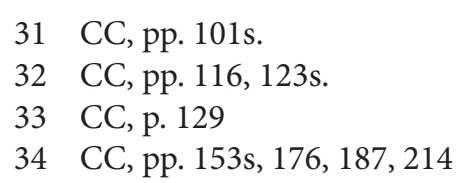


tado $^{35}$. Tal filosofía progresista, secularización de la escatología cristiana, implicaba un programa político que remitía toda acción al futuro, de modo que con la meta de la Historia se garantizaba la victoria pacífica de los ideales morales ${ }^{36}$. Lo relevante es que al identificar la planificación política indirecta con el decurso de la Historia se encubría a la par que se fomentaba la posibilidad de la revolución ${ }^{37}$.

La clave que focaliza Koselleck en el desenlace de la crisis política, ya evidente para Turgot y más aún para Rousseau, es la subordinación de la política a la moral, que invierte los fundamentos del Estado absolutista sin cuestionar su estructura externa. El dualismo permite despojar al Estado de su soberanía pero no de su función, que ahora es función de la sociedad que opera de modo indirecto, mediante una moralización de la política. Es la escisión entre moral y política la que, retirando al Estado sus fundamentos políticos $\mathrm{y}$ encubrir las consecuencias, permite exponer una pretensión política con la legitimidad de lo moral, y así cuestionar la soberanía absoluta sin aparentemente tocarla. La cuestión de la configuración política de un ordenamiento estatal moral es ignorada como tal. Pero, según el schmittiano Koselleck, tal elusión no implica que no exista un auténtico detentador de la soberanía, que impera anónimamente en nombre de la moral ${ }^{38}$.

La conducta apolítica (indirectamente política) de la nueva élite se hizo políticamente consciente en 1770 , reclamando la politización de las leyes morales de la sociedad (a través de una Constitución o el parlamento) y viéndose obligada finalmente a decapitar al monarca. Pero aun así se mantuvo, a juicio de Koselleck, la paradoja de entender el proceso político anti

35 CC, p. 228

36 CC, p. 239.

37 CC, p. $241 \mathrm{n}$.

38 CC, pp. 264s. 267. estatal como tribunal moral, pudiendo tratar la guerra civil como mero desenlace de una jurisdicción moral, la de la filosofía utópica de la Historia que garantizaba la ejecución de los veredictos burgueses ${ }^{39}$.

Llegados aquí, el juicio de Koselleck es abiertamente schmittiano: "Llevada de su desesperación ante su propia incapacidad para reconocer la esencia del poder, se acaba refugiando en la pura violencia. Usurpa el poder con la mala conciencia de un moralista convencido de que el sentido y el fin de la Historia son convertir al poder en algo superfluo" 40 . Tampoco es difícil oír el eco de Catolicismo y forma política en las páginas en que Koselleck recrea el devenir de la forma estatal. El Estado, que sustituyó a la catolicidad en descomposición como estructura formal de orden y jerarquía, creó un ámbito de protección y de neutralidad para garantizar su soberanía. Pero el hombre, integrado en la sociedad apolítica y arreligiosa resultado de la privatización de la religión, halló su verdadera patria en la moral, constituyendo una sociedad civil no integrable ante cuyo asalto indirecto sucumbirá el Estado absolutista $^{41}$.

Según Koselleck, la herencia utópica, moralista y anti estatal de la Ilustración está todavía presente. También hoy el anonimato político dado en la soberanía de la utopía parece haber eliminado la necesidad de decisiones históricas ${ }^{42}$.

5. Una historia de los conceptos contra la aceleración y el progreso liberales

La deuda con las concepciones schmittianas es evidente en Crítica y crisis. Desde la

39 CC, p. 317 ss.

40 CC, p. 338.

41 CC, p. 337.

42 CC, p. 339 
explicación de la génesis de la Ilustración y la revolución a partir de la constitución de una sociedad aglutinada en torno a la moralidad subjetiva que cristaliza en opinión pública, hasta la denuncia de la planificación del futuro por parte de un Estado meramente técnico. Y ello por no hablar de los juicios contra la (aparente) apoliticidad liberal o la filosofía de la Historia burguesa anclada en la fe en el progreso.

Mi hipótesis pasa por defender la unidad del proyecto de Koselleck más allá de sus evidentes variaciones y de las probables inconsistencias. Cabría considerar Futuro pasado la obra que, aún siendo remisible al marco teórico antiliberal (si bien de forma más indirecta o, si se prefiere, oculta), incorpora igualmente las claves que explican el ulterior desarrollo de una reflexión epistemológica sobre la Historia de alcance antropológico, la Histórica (si bien la relación interna es inversa, por cuanto la historia de los conceptos políticos modernos es una de las historias posibilitada por la Histórica, pero no deducible de ésta). La semántica histórica desplegada en Futuro pasado constituye el marco teórico que refleja y posibilita el programa histórico-conceptual desplegado en Geschichtliche Grundbegriffe. Éste permite inferir el interés de Koselleck por identificar la especificidad de Prusia a partir de su limitada recepción de las categorías burguesas y la ausencia de un poder central capaz de arrumbar el cosmos medieval y posibilitar el triunfo de la nueva sociedad -como sucedió en Francia. Ello explica el que los conceptos fundamentales sean los vinculados con el de sociedad civil, permitiendo en la misma medida explicitar las condiciones de posibilidad de dicha sociedad. En este sentido, Crítica y crisis ofrece el marco para comprender la historia de los conceptos y la centralidad del Sattelzeit. Y el escrito de habilitación Preusen zwischen Reform und Revolution (Prusia entre la reforma y la revolución) anticipa la potencialidad de una meto- dología que atiende a los procesos de reconceptualización -desde las guerras napoleónicas hasta la revolución de 1848- de las ideas de ciudadanía, Estado, propiedad, etc.

Todo ello justifica la atención prestada por Koselleck al Sattelzeit, período en el que se desarrolla la nueva subjetividad ética y la teoría del contrato, pero igualmente período en el que se consagra el ideal moderno-contemporáneo de progreso y la planificación y aceleración consecuentes. Así, la exigencia metódica de comparar entre sí el ámbito de experiencia y el horizonte de esperanza de la época cuyos conceptos quieren analizarse es inferida por Koselleck de su tesis sobre la influencia que la experiencia del nuevo tiempo histórico dada en la experiencia de la aceleración tuvo en la terminología sociopolítica, que enriqueció los conceptos tradicionales con un coeficiente temporal, elevándolos a instrumentos de control del movimiento histórico, esto es, a factores de todos los cambios, desde entonces hasta hoy $^{43}$.

El de liberalismo constituiría, entre otros, un concepto fundamental carente, al acuñarse, de contenido experiencial, constituyendo propiamente un programa de futuro orientado a generar nuevas experiencias ${ }^{44}$. Más un factor que un índice, pues. En la medida en que tal concepto se reconoce en los ideales mencionados de progreso acelerado y planificación, es posible interpretar la concepción koselleckiana del tiempo histórico y de los conceptos fundamentales como una denuncia del estilo de

43 R. Koselleck, Futuro pasado. Para una semántica de los tiempos históricos (en adelante, FP), trad. N. Smilg, Paidós, Barcelona, 1993, pp. 75, 83, 111s., 329s. Se cuestiona la absolutización koselleckiana de la ciencia política moderna en S. Chignola, "Historia de los conceptos, historia constitucional, filosofía política. Sobre el problema del léxico político moderno", Res Publica, 11-12, 2003, pp. 27-67.

44 R. Koselleck, "Historia de los conceptos y conceptos de historia", Ayer, 53, 2004, p. 37. 
vida que nos acompaña desde la Modernidad. Una vida a su juicio dominada por la permanente fagocitación de novedades y por la insuperable sensación de obsolescencia que domina cualquier realidad. Es el mundo presidido por la aceleración y fugacidad que consagra la Modernidad postrevolucionaria. Un mundo experimentable por cualquier individuo occidental, que fácilmente se reconoce desfasado en cualquier ámbito de la vida.

Desde esta premisa, es posible contemplar la historia de los conceptos como un antídoto frente a la idealización implícita en la fe en el progreso y a favor de un anclaje en el saber histórico que permita remitir todo avance y toda proyección futura a la experiencia acumulada $\mathrm{y}$, de esta manera, sortear los peligros de crisis política, avanzar sobre suelo firme y superar el prometeísmo implícito en una concepción de la Historia que la contempla como absoluta-mente disponible ${ }^{45}$.

Esta óptica de comprensión de lo implicado en la historia de los conceptos políticos exige focalizar de su teoría elementos tales como las estructuras, que constituyen las condiciones limitantes-posibilitantes de todo cambio y, en esta medida, de todo futuro. Pero que, en la misma medida, legitiman y permiten recuperar el lema de la historia magistra vita. Dicho de otro modo: frente al determinismo y tiranía de la creatividad absoluta, Koselleck recuerda la existencia de estructuras objetivas de larga duración que limitan las posibilidades. Estructuras sin las que serían imposibles los acontecimientos, que se inscriben en distintas profundidades temporales (estratos) y acerca de las cuales los historiadores pueden ilustrarnos, "porque la historia se repite estructuralmen-

45 Se subraya esta perspectiva en F. Oncina, "Experiencia y política en la historia conceptual”, Res publica, 1, 1998, p. 112. te"46. Y como la característica fundamental de un concepto es su capacidad de trascender su contexto originario y proyectarse en el tiempo, la historia de los conceptos libera los conceptos de su contexto y coordina sus significados a través del curso del tiempo, proporcionando claves para reconstruir procesos de largo pla$\mathrm{zO}^{47}$.

La búsqueda de condiciones formales a priori que, a la par que posibilitan, limitan todo cambio y toda acción, encuentra en las categorías "experiencia” y "expectativa" su paradigma. En su objetivo de clarificar qué es eso del tiempo histórico, Koselleck sostiene que para concebirlo es preciso atender a la diferencia entre el pasado y el futuro o, dicho antropológicamente, a la diferencia entre experiencia (el pasado presente) y expectativa (el futuro presente $)^{48}$. Ambas categorías no remiten a una realidad histórica, sino que son formales, permitiendo establecer las condiciones de toda historia posible por cuanto remiten a un dato antropológico sin el que la historia no es ni posible ni concebible ${ }^{49}$.

La tesis de Koselleck es que las expectativas no son totalmente deducibles de la experiencia previa, puesto que en la historia sucede siempre algo más o algo menos de lo contenido en los datos previos, pero que, igualmente, quien no basa su expectativa en su experiencia

46 R. Koselleck, "Sobre la antropología de las experiencias del tiempo histórico", en Los estratos del tiempo: estudios sobre la historia, trad. D. Innerarity, Paidós, Barcelona, 2001, pp. 131, 36ss.

47 FP, pp. 113, 151ss.

48 FP, p. 15.

49 FP, pp. 335ss. El resto de categorías constitutivas de la antropología trascendental (Histórica) evidencia el pesimismo antropológico schmittiano. Así, sostiene la insuperabilidad de la fórmula amigo-enemigo como condición de la política en pp. 244, 250. Igualmente, cf. R. Koselleck, "Historia y hermenéutica”, en R. Koselleck y H.-G. Gadamer, Historia y hermenéutica, trad. F. Oncina, Paidós, Barcelona, 1997, pp. 71-85. 
se equivoca ${ }^{50}$. A su juicio, en la época moderna las expectativas se fueron alejando de las experiencias, pudiéndose concebir la historia como proceso de perfeccionamiento continuo planificado y ejecutado por los hombres, convirtiéndose las planificaciones en legitimaciones de la política ${ }^{51}$. El progreso apuntaba a este mundo y no al más allá, y las expectativas se separaban de lo ofrecido por las experiencias precedentes. De hecho, el de "progreso" fue el concepto que permitió conceptualizar esta experiencia del tiempo como ruptura, como transición en la que reiteradamente aparecen cosas inesperadas. Se trataba de una experiencia cotidiana desde la Revolución Francesa y el desarrollo científico-técnico: que se vive en un tiempo fugaz, de paso, acelerado ${ }^{52}$.

La experiencia de aceleración era el índice de que la diferencia entre experiencia y expectativa sólo se mantiene modificándose continuamente, es decir, cuando los avances político-sociales y científico-técnicos modifican los ritmos del mundo de la vida haciéndoles adquirir una cualidad genuinamente histórica distinta del tiempo natural. Tal experiencia constituye el faktum desde el que Koselleck explica la perentoria necesidad de un concepto de tiempo histórico como realidad diferenciada. A su juicio, dicha experiencia parece haber acabado con la acción de retardamiento ejercida por la Iglesia y el Estado. Ahora es éste, que Schmitt concebía como katechon, quien lidera la aceleración ${ }^{53}$. La deuda de Koselleck con Schmitt se explicita cuando sostiene que, a diferencia del acortamiento apocalíptico del tiempo, que representaba el tránsito a la salvación, la aceleración moderna implica la posibilidad de que el hombre mismo aniquile las condiciones tradicionales de su existencia. De ahí que defienda la necesidad de recurrir a los

50 FP, pp. 266, 341.

51 FP, pp. 342ss.

52 FP, pp. 321, 350s.

53 FP, pp. 64, 37; CC, p. 22. factores de estabilización y a los condicionamientos naturales de nuestra existencia terrestrelo que, en términos políticos, significa saber "quién acelera o retarda a quién o qué, dónde y cuándo" $"$.

Sólo desde una filosofía de la historia resultaba posible domeñar un presente acelerado, y ello en la medida en que tal filosofía progresista incorporaba una nueva conciencia del tiempo que determinó la orientación de la modernidad a un futuro no remisible a la experiencia pasada ${ }^{55}$. Ello eliminó de la Historia su carácter de magistra vitae: si las experiencias nos abocan a un futuro concebido como tarea (el Estado revolucionario se autocomprende como carente de pasado y creador absoluto) y sostenido en su propia naturaleza ignota y sorpresiva (indeducible, como la Revolución), entonces el pasado parece impotente como fuente de conocimiento ${ }^{56}$. La Historia deja de ser contemplada como destino y pasa a ser vista como proceso de autorrealización humana $y$, en esta medida, como disponible y planificable. Y es justamente el deber moral lo que impone proyectar el futuro, reduciendo la historia a la ejecución temporalizada de la moral $^{57}$.

\section{Conclusión}

Hemos comprobado que, según Koselleck, las filosofías de la historia permiten com-

54 R. Koselleck, Aceleración, prognosis y secularización, , trad. F. Oncina, Pre-Textos, Valencia, 2003, p. 71.

55 FP, pp. 36s., 59.

56 FP, pp. 62, 89, 348s. Para E. J. Palti, la defensa de una quiebra tajante entre las filosofías modernas de la historia y el antiguo lema ciceroniano supondría proyectar sobre el siglo XVIII categorías del historicismo organicista del siglo XIX. Cf. "Koselleck y la idea de Sattelzeit. Un debate sobre modernidad y temporalidad", Ayer, 53, 2004, pp. 73s.

57 R. Koselleck, historia/Historia, trad. A. Gómez Ramos, Trotta, Madrid, 2004, pp. 106, 146. 
prender la modernidad como época en la que pierde todo sentido el lema historia magistra vitae, inviable desde la nueva experiencia del tiempo. Durante dicha época se democratizan e ideologizan los conceptos políticos, se legitima la crítica y se temporaliza la experiencia. La tesis de la historia conceptual es que tales transformaciones, registradas por los cambios de los significados de los conceptos, definen la modernidad como umbral genético de nuestras propias concepciones de lo social y de lo político, tornando plenamente actuales sus patologías.

Junto a tesis reduccionistas sobre la opinión pública ${ }^{58}$ o en la propia caracterización de la Ilustración ${ }^{59}$, o problemáticas aplicaciones del teorema de la secularización a la categoría de aceleración ${ }^{60}$, por no hablar de los inasumibles presupuestos "comunitaristas-estatalistas" schmittianos, el pensamiento de Koselleck contiene argumentos persuasivos en orden a detectar las causas y los efectos del estilo de vida acelerada que nuestra época ha heredado de aquel "tiempo moderno". Tal aceleración no debe reducirse a la experiencia personal de que vamos a la zaga de las innovaciones de todo tipo -con ser ello importante-, sino que es preciso contemplarla desde un punto de vista más abstracto (propiamente histórico-conceptual) para aprehender el alcance (claramente schmittiano) del envite de Koselleck. Porque lo

58 Habermas criticó la demonización koselleckiana de la opinión pública, que la considera germen de guerra civil, sosteniendo que es principio de racionalización de la política mediante el diálogo, y no mera moralización. J. Habermas, Perfiles filosófico-políticos, trad. M. Jiménez Redondo, Taurus, Madrid, 1986, pp. 383ss.

59 Cf. F. Oncina, "El arcano: entre la postrevolución y la contrarrevolución”, en R. R. Aramayo, J. Muguerza y A. Valdecantos (comps.), El individuo y la historia, Paidós, Barcelona, 1995, pp. 215-249.

60 Cf. J. L. Villacañas, "Acerca del uso del tiempo apocalíptico en la Edad Media”, Isegoría, 37, 2007, pp. 81-96. que está en cuestión es la capacidad (y la legitimidad) del Estado (y, más en general, de la política) para ejercer el rol de katechon que para él reivindicara Schmitt. Nadie como el jurista de Plettenberg ha captado la profundidad de los versículos paulinos sobre el acortamiento apocalíptico del tiempo (1 Cor 7, 29-32), sus efectos (mesiánicos, anómicos, revolucionarios) presentes y el katechon que procura retardarlos ${ }^{61}$. Koselleck ya evidencia una conciencia poco esperanzada en la capacidad de lo político-estatal para frenar la aceleración moderna, herencia secularizada y transmutada de la cristiana. Él es sabedor (antes lo fue Schmitt) de que el Estado neutral y tecnicista, esclavo de la economía y revestido de moralismo (hacia dentro y hacia fuera), favorece la planificación y la aceleración, no las retarda.

Frente a la vida acelerada contemporánea instalada en un permanente Aufhebung sin objetivo, determinada casi en exclusiva por la prevalencia de la lógica tecnocientífica afín al capitalismo -tenuemente edulcorada por vagos y cambiantes principios morales-, ignorante de la estabilidad de las estructuras y de ciertas condiciones antropológicas, la sugerencia de Koselleck pasará finalmente por recuperar la conciencia de éstas, la desidealización del lenguaje político que motivan, el sentido vital que vehiculan y el ejercicio de responsabilidad y de memoria que posibilitan.

61 C. Schmitt, El nomos de la tierra, trad. D. Schilling, Comares, Granada, 2002, pp. 22-26, 54. La referencia es a 2 Tes. 
